\title{
HOXB13 is a susceptibility gene for prostate cancer: results from the International Consortium for Prostate Cancer Genetics (ICPCG)
}

\author{
Jianfeng Xu $\cdot$ Ethan M. Lange $\cdot$ Lingyi Lu $\cdot$ Siqun L. Zheng $\cdot$ Zhong Wang $\cdot$ Stephen N. Thibodeau • \\ Lisa A. Cannon-Albright $\cdot$ Craig C. Teerlink - Nicola J. Camp • Anna M. Johnson • Kimberly A. Zuhlke • \\ Janet L. Stanford · Elaine A. Ostrander · Kathleen E. Wiley · Sarah D. Isaacs • Patrick C. Walsh • \\ Christiane Maier • Manuel Luedeke $\cdot$ Walther Vogel • Johanna Schleutker • Tiina Wahlfors • \\ Teuvo Tammela • Daniel Schaid • Shannon K. McDonnell • Melissa S. DeRycke • Geraldine Cancel-Tassin • \\ Olivier Cussenot · Fredrik Wiklund · Henrik Grönberg • Ros Eeles • Doug Easton • Zsofia Kote-Jarai • \\ Alice S. Whittemore · Chih-Lin Hsieh · Graham G. Giles • John L. Hopper • Gianluca Severi • \\ William J. Catalona $\cdot$ Diptasri Mandal $\cdot$ Elisa Ledet $\cdot$ William D. Foulkes $\cdot$ Nancy Hamel $\cdot$ Lovise Mahle $\cdot$ \\ Pal Moller - Isaac Powell · Joan E. Bailey-Wilson · John D. Carpten · Daniela Seminara - Kathleen A. Cooney • \\ William B. Isaacs • International Consortium for Prostate Cancer Genetics
}

Received: 13 July 2012/ Accepted: 15 September 2012/Published online: 12 October 2012

(C) The Author(s) 2012. This article is published with open access at Springerlink.com

\begin{abstract}
Prostate cancer has a strong familial component but uncovering the molecular basis for inherited susceptibility for this disease has been challenging. Recently, a rare, recurrent mutation (G84E) in $H O X B 13$ was reported to be associated with prostate cancer risk. Confirmation and
\end{abstract}

K. A. Cooney and W. B. Isaacs are Co-Senior Authors.

Electronic supplementary material The online version of this article (doi:10.1007/s00439-012-1229-4) contains supplementary material, which is available to authorized users.

J. Xu $\cdot$ L. Lu $\cdot$ S. L. Zheng $\cdot$ Z. Wang

Data Coordinating Center for the ICPCG, Wake Forest

University School of Medicine, Winston-Salem, NC, USA

J. Xu $\cdot$ L. Lu $\cdot$ S. L. Zheng $\cdot$ Z. Wang

Center for Cancer Genomics, Wake Forest University School of

Medicine, Winston-Salem, NC, USA

E. M. Lange - A. M. Johnson - K. A. Zuhlke - K. A. Cooney University of Michigan ICPCG Group, University of Michigan Medical School, Ann Arbor, MI, USA

E. M. Lange

Departments of Genetics and Biostatistics, University of North Carolina, Chapel Hill, NC, USA

S. N. Thibodeau · D. Schaid · S. K. McDonnell •

M. S. DeRycke

Mayo Clinic ICPGC Group, Mayo Clinic, Rochester, MN, USA

S. N. Thibodeau · M. S. DeRycke

Department of Laboratory Medicine and Pathology, Mayo

Clinic, Rochester, MN, USA characterization of this finding is necessary to potentially translate this information to the clinic. To examine this finding in a large international sample of prostate cancer families, we genotyped this mutation and 14 other SNPs in or flanking $H O X B 13$ in 2,443 prostate cancer families recruited by the International Consortium for Prostate Cancer Genetics (ICPCG). At least one mutation carrier was found in 112 prostate cancer families (4.6\%), all of European descent. Within carrier families, the G84E mutation was more common in men with a diagnosis of

L. A. Cannon-Albright · C. C. Teerlink · N. J. Camp

University of Utah ICPCG Group, University of Utah School of Medicine, Salt Lake City, UT, USA

L. A. Cannon-Albright · C. C. Teerlink · N. J. Camp Department of Medicine, University of Utah School of Medicine, Salt Lake City, UT, USA

A. M. Johnson - K. A. Zuhlke · K. A. Cooney

Department of Internal Medicine, University of Michigan Medical School, Ann Arbor, MI, USA

J. L. Stanford - E. A. Ostrander

Fred Hutchinson Cancer Research Center (FHCRC) ICPCG

Group, Seattle, WA, USA

J. L. Stanford

Division of Public Health Sciences, FHCRC, Seattle, WA, USA

E. A. Ostrander

Cancer Genetics Branch, National Human Genome Research Institute, NIH, Bethesda, MD, USA 
prostate cancer (194 of 382, $51 \%$ ) than those without (42 of $137,30 \%), P=9.9 \times 10^{-8}$ [odds ratio $4.42(95 \%$ confidence interval 2.56-7.64)]. A family-based association test found G84E to be significantly over-transmitted from parents to affected offspring $\left(P=6.5 \times 10^{-6}\right)$. Analysis of markers flanking the G84E mutation indicates that it resides in the same haplotype in $95 \%$ of carriers, consistent with a founder effect. Clinical characteristics of cancers in mutation carriers included features of high-risk disease. These findings demonstrate that the $H O X B 13$ G84E mutation is present in $\sim 5 \%$ of prostate cancer families, predominantly of European descent, and confirm its association with prostate cancer risk. While future studies are needed to more fully define the clinical utility of this observation, this allele and others like it could form the basis for early, targeted screening of men at elevated risk for this common, clinically heterogeneous cancer.

\section{Introduction}

By sequencing coding regions of more than 200 genes in a previously identified region of linkage at 17q21-22 (Lange et al. 2003; Gillanders et al. 2004; Xu et al. 2005; Lange et al. 2007; Cropp et al. 2011) a rare but recurrent mutation (G84E) in $H O X B 13$ was recently identified in four of 94

K. E. Wiley · S. D. Isaacs · P. C. Walsh · W. B. Isaacs Johns Hopkins University ICPCG Group, Baltimore, MD, USA

K. E. Wiley · S. D. Isaacs · P. C. Walsh · W. B. Isaacs ( $₫)$ Department of Urology, Johns Hopkins Medical Institutions, Johns Hopkins Hospital, Marburg 115, 600 North Wolfe Street, Baltimore, MD 21287, USA

e-mail: wisaacs@jhmi.edu

C. Maier · M. Luedeke · W. Vogel

University of Ulm ICPCG Group, University of Ulm, Ulm, Germany

C. Maier · M. Luedeke

Department of Urology, University of Ulm, Ulm, Germany

W. Vogel

Institute of Human Genetics, University of Ulm, Ulm, Germany

J. Schleutker · T. Wahlfors · T. Tammela

University of Tampere ICPCG Group, University of Tampere and Fimlab Laboratories, Tampere, Finland

J. Schleutker · T. Wahlfors

Institute of Biomedical Technology/BioMediTech, University of

Tampere and Fimlab Laboratories, Tampere, Finland

J. Schleutker

Department of Medical Biochemistry and Genetics, University of Turku, Turku, Finland probands from prostate cancer families. (Ewing et al. 2012) The mutation co-segregated with prostate cancer in these four families and was found to be significantly more common among 5,083 unrelated prostate cancer patients $(1.4 \%)$ than control subjects $(0.1 \%)$ of European descent $\left(p=8.5 \times 10^{-7}\right)$ leading to odds ratio (OR) estimates of tenfold or more. In this initial report, the frequency of the mutation was higher in prostate cancer patients with earlyonset disease (age at diagnosis $\leq 55$ years old, $2.2 \%$ ) or with a positive family history $(2.2 \%)$, and most common in patients with both of these features $(3.1 \%)$. If confirmed, these findings provide support for the concept that rare, moderately penetrant mutations as well as common, low-penetrance prostate cancer risk-associated variants identified from genome-wide association studies (GWAS) (Gudmundsson et al. 2007a, b, 2008, 2009; Yeager et al. 2007, 2009; Thomas et al. 2008; Eeles et al. 2008, 2009; Sun et al. 2008; Xu et al. 2010; Kote-Jarai et al. 2011a; Takata et al. 2010; Akamatsu et al. 2012; Haiman et al. 2011) both contribute to prostate cancer risk. The identification and characterization of genetic variants reproducibly associated with substantial increases in prostate cancer risk would provide enhanced ability to identify men most likely to benefit from early disease screening.

Prostate cancer demonstrates wide differences in incidence and mortality across populations within the United

\section{T. Tammela}

Department of Urology, Tampere University Hospital, Tampere, Finland

D. Schaid · S. K. McDonnell

Department of Health Sciences Research, Mayo Clinic,

Rochester, MN, USA

G. Cancel-Tassin · O. Cussenot

CeRePP ICPCG Group, Paris, France

G. Cancel-Tassin

CeRePP UPMC University, Paris, France

O. Cussenot

Department of Urology, APHP, Hospital Tenon, Paris, France

F. Wiklund · H. Grönberg

Karolinska ICPCG Group, Karolinska Institutet, Stockholm, Sweden

F. Wiklund · H. Grönberg

Department of Medical Epidemiology and Biostatistics,

Karolinska Institutet, Stockholm, Sweden

R. Eeles · D. Easton · Z. Kote-Jarai - G. G. Giles ·

J. L. Hopper · G. Severi · W. D. Foulkes · N. Hamel ·

L. Mahle · P. Moller

ACTANE (Anglo/Canadian/Texan/Australian/Norwegian/EU

Biomed) Consortium ICPCG Group, Surrey, UK 
States and throughout the world. In an attempt to confirm and expand the observations of Ewing et al. (2012), we examined the frequency of $H O X B 13$ G84E mutations in prostate cancer families across different ancestries and geographic regions. We genotyped this mutation and other known variants in $H O X B 13$ in 2,443 hereditary prostate cancer families recruited by members of the International Consortium for Prostate Cancer Genetics (ICPCG), a large NCI-funded collaborative resource for studies of genetic susceptibility for hereditary prostate cancer.

\section{Subjects and methods}

\section{Study population}

The ICPCG study cohort has been described in detail previously (Schaid and Chang 2005; Xu et al. 2005). Fifteen groups participated in the present study, including those from Europe [Finland (Tampere University), Sweden (Karolinska Institute), UK (Institute of Cancer Research and Royal Marsden NHS Foundation Trust, University of Cambridge, ACTANE), Germany (University of Ulm), and France (CeRePP)], North America (Fred Hutchinson Cancer Research Center, Johns Hopkins Hospital, Louisiana

R. Eeles $\cdot$ Z. Kote-Jarai

Institute of Cancer Research and Royal Marsden NHS

Foundation Trust, Surrey, UK

D. Easton

Strangeways Laboratory, Department of Oncology,

Centre for Cancer Genetic Epidemiology,

University of Cambridge, Cambridge, UK

A. S. Whittemore - C.-L. Hsieh

BC/CA/HI ICPCG Group, Stanford School of Medicine,

Stanford, CA, USA

\section{A. S. Whittemore}

Department of Health Research and Policy, Stanford School of Medicine, Stanford, CA, USA

\author{
A. S. Whittemore \\ Stanford Comprehensive Cancer Center, Stanford School of \\ Medicine, Stanford, CA, USA \\ C.-L. Hsieh \\ Department of Urology and Department of Biochemistry and \\ Molecular Biology, University of Southern California, Los \\ Angeles, CA, USA \\ G. G. Giles · J. L. Hopper · G. Severi \\ Cancer Epidemiology Centre, Cancer Council Victoria, \\ Melbourne, Australia \\ G. G. Giles · J. L. Hopper · G. Severi \\ Centre for Molecular, Environmental, Genetic and Analytical \\ Epidemiology, University of Melbourne, Melbourne, Australia
}

State University, Mayo Clinic, McGill University, Northwestern University, Stanford University, University of Michigan, and University of Utah), and Australia (University of Melbourne) (Supplementary Table 1).

Each ICPCG group recruited its study population via different methods of pedigree ascertainment and utilized different methods to confirm prostate cancer diagnosis. In this study, men were considered "affected" if their prostate cancer diagnosis was confirmed by either medical records or death certificates. All other men were assigned as "unknown phenotype." A total of 2,443 families were included in the study, including 6,422 affected men and 1,902 men without a prostate cancer diagnosis (unknown), and 1,803 women whose DNA samples were available (Supplementary Table 1). Research protocols and study documentation were approved by each group's Institutional Review Board.

SNPs selection and genotyping

Five mutations in the $H O X B 13$ gene, selected from the original paper of Ewing et al. (2012) and the ESP database (Exome Variant Server, NHLBI Exome Sequencing Project, Seattle, WA, USA (URL: http://evs.gs.washington. edu/EVS/) [1/2012]) were genotyped in the ICPCG

W. J. Catalona

Northwestern University ICPCG Group, Chicago, IL, USA

W. J. Catalona

Northwestern University Feinberg School of Medicine,

Chicago, IL, USA

D. Mandal · E. Ledet

Louisiana State University ICPCG Group, New Orleans,

LA, USA

D. Mandal · E. Ledet

Department of Genetics, Louisiana State University Health Sciences Center, New Orleans, LA, USA

W. D. Foulkes · N. Hamel

Program in Cancer Genetics, Departments of Oncology and Human Genetics, McGill University, Montreal, QC, Canada

W. D. Foulkes · N. Hamel

Research Institute of the McGill University Health Centre, Montreal, QC, Canada

L. Mahle $\cdot$ P. Moller

The Norwegian Radium Hospital, Oslo, Norway

I. Powell · J. E. Bailey-Wilson · J. D. Carpten

African American Hereditary Prostate Cancer ICPCG Group, Detroit, MI, USA

I. Powell

Karmanos Cancer Institute, Wayne State University, Detroit, MI, USA 
dataset, including G84E (c.251G > A, rs138213197), T105I (c.314C > T, rs140492479), R217C (c.649C > T, rs13945 791), R229G (c.685C > G), and T253P (c.757A > C). In addition, ten polymorphic SNPs (rs890435, rs2326017, rs7212669, rs8064938, rs3809773, rs1054072, rs8556, rs3809771, rs4793980, rs3110601) flanking the $H O X B 13$ gene and spanning 108,191 base pairs (bp) from $46,719,399$ to $46,827,590$ (Build 37) were genotyped to estimate allele frequencies and haplotypes. The G84E mutation, due to a change in the second position of codon 84 (GGA $\rightarrow$ GAA), results in a nonconservative substitution in a conserved putative protein-protein binding motif of HOXB13 (Ewing et al. 2012).

Genotyping was performed using the MassARRAY iPLEX (Sequenom, Inc., San Diego, CA, USA). Duplicates and negative controls were included in each 96-well plate to ensure quality control (QC). Genotyping was performed by technicians blinded to the sample status. The average concordance rate was $99.7 \%$ for 6,300 genotypes among QC duplicates.

\section{Statistical methods}

Frequency of the G84E mutation was determined at either family level or individual level. At a family level, the proportion of families with at least one G84E mutation carrier was determined for the entire set as well as for each ICPCG group. The difference in the proportion among different ICPCG groups was tested using Chi-square with a degree of freedom $(d f)$ of 14 . At an individual level, the proportion of G84E mutation carriers was compared among men with a diagnosis of prostate cancer (affecteds) and the remaining men within the families (unknowns). The difference of G84E mutation carrier rate between affected and unknown men was tested based on a marginal model that accounts for relatedness of subjects within families using generalized estimating equations (GEE). An exchangeable working correlation matrix was assumed.

A family-based association test was performed to test association of the G84E mutation and other SNPs with prostate cancer by assessing over-transmission of alleles from parents to affected offspring using the computer program FBAT (Xu et al. 2002). Empirical variance test

\section{J. E. Bailey-Wilson}

Inherited Disease Research Branch, National Human Genome Research Institute, NIH, Bethesda, MD, USA

\section{J. D. Carpten}

Genetic Basis of Human Disease Research Division,

Translational Genomics Research Institute, Phoenix, AZ, USA

D. Seminara

National Cancer Institute, NIH, Bethesda, MD, USA statistics were used to account for the correlation of transmitted alleles among multiple affected individuals in the same family.

Haplotypes of each individual based on these 15 SNPs were estimated using Genehunter-plus (Kruglyak et al. 1996) and PLINK (Purcell et al. 2007). The haplotypes with the highest likelihood were selected. For subjects whose inferred haplotypes were different based on these two methods, manual inspection was performed to resolve the difference, with priority given to haplotypes based on linkage disequilibrium among markers in this study population.

\section{Results}

Among five previously observed mutations in $H O X B 13$ (Ewing et al. 2012) two were observed in this studyR217C (rs13945791) and G84E (rs138213197). The rare $\mathrm{R} 217 \mathrm{C}$ variant was found one time each in two families of European descent and did not co-segregate with prostate cancer. The G84E mutation was found in 283 subjects from 112 families of European descent, including 194 men with prostate cancer (Table 1). This represented $4.6 \%$ of all 2,443 prostate cancer families and $4.8 \%$ of 2,298 prostate cancer families of European descent. The proportion of families with at least one G84E mutation carrier differed significantly across the 15 ICPCG groups $(P=9.4 \times$ $\left.10^{-8}\right)$. The proportion was highest in families from the Nordic countries of Finland $(22.4 \%)$ and Sweden $(8.2 \%)$ and lower in North America (0-6.1\%) and Australia $(2.6 \%)$. The G84E mutation was not found in families of any other race or ethnicity, including those of African $(N=58)$, Ashkenazi Jewish $(N=46)$, or other descent $(N=28)$. Obviously, larger numbers of families of these and other races and ethnicities will need to be examined to more fully characterize the population distribution of this mutation.

In the 112 families with at least one G84E mutation carrier, the mutation was found in both affected and unaffected men. However, the carrier rate was significantly higher in affected men (194 of 382, $51 \%$ ) than other men in these families (i.e. men of unknown status [(42 of 137, $\left.\left.31 \%), p=9.9 \times 10^{-8}\right]\right)$ (Table 1). Using a statistical test that considered the relatedness of subjects within carrier families, the odds ratio (OR) for prostate cancer was 4.42 [95\% confidence interval (CI) 2.56-7.64] for the G84E mutation carriers. We repeated our analyses excluding families from the University of Michigan and Johns Hopkins Hospital, some of which were included in the initial report describing $H O X B 13$ as a prostate cancer susceptibility gene (Ewing et al. 2012). In particular, the former study included $H O X B 13$ G84E genotype data from only the 


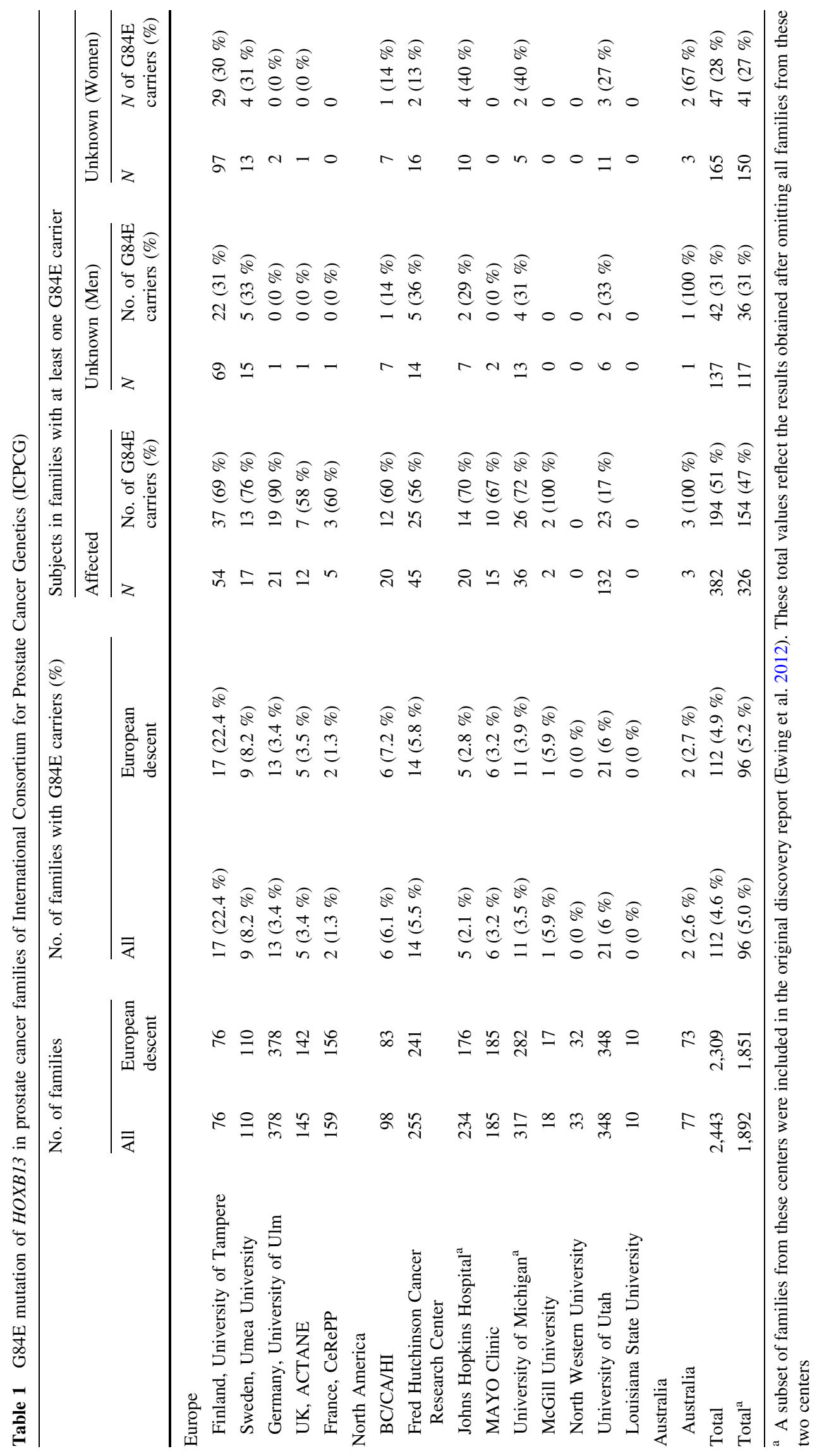


Table 2 Family-based association test for SNPs at HOXB13 region in ICPCG families

\begin{tabular}{|c|c|c|c|c|c|c|c|c|c|c|c|}
\hline $\mathrm{Chr}$ & Position & $\mathrm{rs} \#$ & Gene & Mutation & $\begin{array}{l}\text { Rare } \\
\text { allele }\end{array}$ & $\begin{array}{l}\text { Allele } \\
\text { frequency }\end{array}$ & $\begin{array}{l}\text { No. of informative } \\
\text { families }\end{array}$ & $\mathrm{S}-\mathrm{E}(\mathrm{S})^{\mathrm{a}}$ & $\operatorname{Var}(\mathrm{S})$ & $Z$ & $P$ \\
\hline 17 & $46,719,399$ & rs890435 & Intergenic & & G & 0.41 & 509 & -7.38 & 243.77 & -0.47 & 0.64 \\
\hline 17 & $46,720,565$ & rs2326017 & Intergenic & & $\mathrm{T}$ & 0.33 & 496 & 3.10 & 248.24 & 0.20 & 0.84 \\
\hline 17 & $46,727,289$ & rs7212669 & Intergenic & & G & 0.10 & 244 & -4.89 & 107.42 & -0.47 & 0.64 \\
\hline 17 & $46,780,829$ & rs8064938 & Intergenic & & A & 0.16 & 353 & -6.12 & 136.42 & -0.52 & 0.60 \\
\hline 17 & $46,784,039$ & rs3809773 & Intergenic & & A & 0.33 & 485 & 1.42 & 245.54 & 0.10 & 0.93 \\
\hline 17 & $46,799,812$ & rs1054072 & PRAC & & $\mathrm{C}$ & 0.47 & 518 & -13.41 & 268.62 & -0.82 & 0.41 \\
\hline 17 & $46.804,250$ & & HOXB13 & $\mathrm{T} 253 \mathrm{P}$ & & 0 & 0 & N/A & N/A & N/A & N/A \\
\hline 17 & $46,804,322$ & & HOXB13 & R229G & G & 0.0001 & 1 & -0.40 & 0.16 & -1.00 & 0.32 \\
\hline 17 & $46,804,358$ & rs139475791 & HOXB13 & $\mathrm{R} 217 \mathrm{C}$ & A & 0.0001 & 2 & -1.60 & 1.36 & -1.37 & 0.17 \\
\hline 17 & $46,805,590$ & rs8556 & HOXB13 & & $\mathrm{T}$ & 0.15 & 342 & -10.77 & 145.60 & -0.89 & 0.37 \\
\hline 17 & $46,805,642$ & rs140492479 & HOXB13 & T105I & A & 0.0001 & 2 & 1.64 & 1.41 & 1.38 & 0.17 \\
\hline 17 & $46,805,705$ & rs138213197 & HOXB13 & G84E & A & 0.02 & 38 & 17.50 & 15.07 & 4.51 & $6.53 \mathrm{E}-06$ \\
\hline 17 & $46,807,919$ & rs3809771 & $5^{\prime}$ & & G & 0.06 & 171 & -8.92 & 64.24 & -1.11 & 0.27 \\
\hline 17 & $46,813,531$ & rs4793980 & $5^{\prime}$ & & $\mathrm{T}$ & 0.16 & 306 & 2.22 & 116.03 & 0.21 & 0.84 \\
\hline 17 & $46,827,590$ & rs3110601 & $5^{\prime}$ & & $\mathrm{C}$ & 0.12 & 274 & -7.46 & 114.18 & -0.70 & 0.49 \\
\hline
\end{tabular}

Based on an FBAT analysis of 2,437 pedigrees (10,217 nuclear families; 40,246 subjects)

${ }^{a} \mathrm{~S}-\mathrm{E}(\mathrm{S})$ is the statistical score for the observed number of rare allele transmissions minus the statistical score for the expected number of transmissions

Table 3 G84E HOXB13 mutation carriers among randomly selected affected probands and their relatives

\begin{tabular}{|c|c|c|c|c|c|c|c|c|}
\hline \multirow{2}{*}{$\begin{array}{l}\text { Proband G84E } \\
\text { Carrier }\end{array}$} & \multicolumn{4}{|c|}{ G84E carriers in first-degree relatives } & \multicolumn{4}{|c|}{ G84E carriers in second-degree relatives or higher } \\
\hline & Affected & Unknown & OR $(95 \% \mathrm{CI})$ & $P$ value & Affected & Unknown & OR $(95 \%$ CI $)$ & $P$ value \\
\hline Yes (51) & $56 / 75(74.7 \%)$ & $16 / 34(47.6 \%)$ & $4.26(1.69-10.75)$ & 0.002 & $11 / 19(57.9 \%)$ & $9 / 39(23.1 \%)$ & $4.81(1.64-14.12)$ & 0.004 \\
\hline No $(1,755)$ & $21 / 2,502(0.8 \%)$ & $3 / 759(0.4 \%)$ & $2.31(0.82-6.51)$ & 0.11 & $15 / 973(1.5 \%)$ & $6 / 651(0.9 \%)$ & $2.21(0.39-12.71)$ & 0.37 \\
\hline
\end{tabular}

youngest prostate cancer case in a subset of University of Michigan and Johns Hopkins Hospital families. The carrier rate in ICPCG families remained significantly higher in affected men (154 of $326,47 \%)$ than unknown men [(36 of $\left.117,31 \%), P=3.3 \times 10^{-6}\right]$ and the OR for prostate cancer was 4.3 [95\% confidence interval (CI) 2.32-7.96] for the G84E mutation carriers after excluding all families from these two institutions (Table 1).

A mixed pattern of co-segregation of the G84E mutation with prostate cancer was found in these 112 families. While complete co-segregation was found in 34 families, incomplete co-segregation was more commonly observed, revealing genetic heterogeneity (affected but not carriers) and incomplete penetrance of the mutation (carriers but unaffected men).

We also examined transmission of G84E mutation and alleles of other genotyped SNPs at the region in all 2,443 families using a family-based association test (Table 2). The risk allele (A) corresponding to the G84E mutation was observed to be transmitted significantly more often than expected from parents to affected sons $\left(P=6.5 \times 10^{-6}\right)$. A significant result was also observed when all families from the University of Michigan and Johns Hopkins Hospital were removed from this analysis $\left(P=1.2 \times 10^{-4}\right) \quad($ Supplementary Table 2$)$, strongly indicating the G84E mutation is associated with prostate cancer risk.

To assess association in our family set while adjusting for variable pedigree structures, we randomly selected one affected man (proband) in the second generation from each of 2,443 pedigrees and then counted the number of G84E carriers among probands, first-relatives, and second-degree relatives or higher (Table 3). The G84E mutation carrier rate among probands was $2.8 \%$. Among the first-degree relatives, the carrier rate was significantly higher in affected men $(75 \%)$ than in those with an unknown phenotype $(48 \%), P=0.002, \quad \mathrm{OR}=4.26 \quad(95 \% \quad \mathrm{CI}$ 1.69-10.75). Among the second-degree relatives or higher, the carrier rate was also significantly higher in affected men $(58 \%)$ than in unknown men $(23 \%), P=0.004$, $\mathrm{OR}=4.81$ (95\% CI 1.64-14.12).

The prostate cancer patients who carried the mutation had a wide spectrum of clinical disease, including cancers with high risk of disease progression (Table 4), as 
Table 4 Clinicopathologic variables of prostate cancers in $\mathrm{HOXB13}$ G84E carriers

\begin{tabular}{lcl}
\hline & No. of patients & $\%$ of patients \\
\hline Tumor grade (Gleason Score) & \\
$\leq 6$ & 67 & 63.2 \\
7 & 32 & 30.2 \\
8 & 4 & 3.8 \\
$\geq 9$ & 3 & 2.8 \\
Tumor stage & & \\
T1c or lower & 47 & 39.2 \\
T2 & 41 & 34.2 \\
T3 or higher & 32 & 26.7 \\
Metastasis at diagnosis & & \\
Yes & 4 & 3.1 \\
Serum PSA level at diagnosis & \\
$\leq 10$ & 49 & 48.0 \\
$11-20$ & 25 & 24.5 \\
$\geq 20$ & 28 & 27.5 \\
Age at diagnosis & & \\
$\leq 55$ & 24 & 18.6 \\
$56-80$ & 105 & 0.0 \\
$\geq 80$ & 0 & 7.0 \\
Death from prostate cancer & 9 & \\
Yes & & \\
\hline
\end{tabular}

indicated by moderate to poor tumor differentiation (tumor grade of Gleason score 7 or higher) in over one-third of the cases with available data, and over one-quarter having nonorgan confined disease at diagnosis (tumor stage $\mathrm{T} 3$ or higher). The mean age at diagnosis of carriers was 62.8 years. In comparison, the mean age at diagnosis for the 6,172 prostate cancer patients without the mutation was 64.4 years $(P=0.04$; relatedness of subjects within families was considered). The mean age at last contact of G84E carriers without a prostate cancer diagnosis was 56.3.

Finally, to assess a potential founder effect for the G84E mutation, we estimated haplotypes based on the 15 genotyped SNPs in this region. The mutation (allele A) of G84E was predicted to be on eight different haplotypes. However, $95 \%$ (269 out of 283) of the occurrences were predicted to be on a single rare haplotype (frequency of $2 \%$ ). Among the 269 G84E mutation carriers predicted to carry the common haplotype, 83 were from Finland while the remaining were from 12 other ICPCG groups. One individual from Finland was homozygous for all 15 markers, allowing unambiguous assignment of the haplotype. This individual was diagnosed with moderately differentiated (Gleason 7), clinically localized prostate cancer at age 60 .

We note that the genotype data for all 269 G84E mutation carriers were consistent with a single shared haplotype spanning the 15 genotyped SNPs (i.e. there were no SNPs that had homozygous genotypes for opposite alleles among the 269 carriers) and it is possible that with additional genotype data the most likely haplotype configuration for G84E carriers would be a single founder haplotype.

\section{Discussion}

By evaluating germline mutations of the $\mathrm{HOXB} 13$ gene in 2,433 prostate cancer families from the ICPCG, this study confirmed the observation that the G84E mutation is significantly associated with prostate cancer in subjects of European descent with family history of the disease. The results remained significant when families used in the original report were not included in the analysis, providing independent confirmation of the original finding. Although there is a large degree of variability in the number of individuals sampled per pedigree in the ICPCG, approximately $5 \%$ of prostate cancer families had at least one member with the G84E mutation. These results are consistent with the hypothesis that $\mathrm{HOXB13}$ G84E is a prostate cancer susceptibility allele that significantly increases the risk of prostate cancer.

The search for hereditary prostate cancer genes has been challenging due to a number of factors including the lateonset nature of the disease and the high background rate of sporadic disease in the general population. Although rare variants of other genes such as RNASEL (Carpten et al. 2002), MSRI (Xu et al. 2002), and ELAC2 (Tavtigian et al. 2001) have been previously identified in prostate cancer families and proposed as prostate cancer susceptibility alleles, follow-up studies have not supported their candidacy. On the other hand, mutations in BRCA2 have been reproducibly associated with prostate cancer risk (Edwards et al. 2003), but their frequency is low in prostate cancer families (Agalliu et al. 2007; Kote-Jarai et al. 2011b).

More recently, GWAS studies have led to the identification of over 40 prostate cancer risk-associated SNPs that have been replicated in multiple study populations. These variants are common in the general population (5\% or higher), confer low risk with ORs, typically in the range of 1.1-1.4 (Gudmundsson et al. 2007a, b, 2008, 2009; Yeager et al. 2007, 2009; Thomas et al. 2008; Eeles et al. 2008, 2009; Sun et al. 2008; Xu et al. 2010; Kote-Jarai et al. 2011a; Takata et al. 2010; Akamatsu et al. 2012; Haiman et al. 2011), and have been estimated to account for $\sim 25 \%$ of the risk associated with a positive family history (Kote-Jarai et al. 2011a). Although more common prostate cancer risk-associated variants are likely to be identified in the future, rare variants with larger effects have been proposed as an alternative mechanism to account for 'missing inheritance' (Iyengar and Elston 2007; Bodmer and Bonilla 2008). In this respect, the establishment of a 
rare and moderate- to high-penetrance mutation in $H O X B 13$ as a prostate cancer susceptibility allele provides empirical evidence for this alternative hypothesis. Indeed, like colorectal and breast cancer, at least some significant fraction of prostate cancer risk is conferred by this class of coding sequence variants.

The estimated frequency of the HOXB13 G84E mutation in prostate cancer families is influenced by the number of individuals in any given family as well as family structure. For example, some extended families, particularly in the Utah collection, have more than 100 subjects and have multiple affected generations. Similarly, estimated ORs for G84E in relation to prostate cancer risk are impacted by the mixed degrees of relatedness among relatives, as the covariance matrices used in the GEE models do not explicitly account for family structure. The analysis presented in Table 3 was designed to provide better odds ratio estimates for first- and second-degree relatives of G84E carriers. Of interest, the carrier rate was lower among second-degree affected relatives (58\%) compared with first-degree affected relatives $(75 \%)$, suggesting the presence of genetic heterogeneity across families. The OR estimates from our analyses should be interpreted only in the context of the current study. We note that the odds ratios are calculated based on many "controls" that have limited phenotype information; most have not been screened for disease or screening results are missing. Further, familial controls not currently affected by prostate cancer are more likely to develop disease in the future compared with randomly selected men from the general population given the strong history of disease in these families. Finally, our familial cases are more likely to carry moderate to high penetrance risk alleles compared with typical unselected prostate cancer cases. Large populationbased studies that include screened men will be necessary to obtain more accurate measures of G84E mutation frequency and penetrance. As we observed, the frequency of G84E mutations are likely population specific.

Our results implicate a geographical frequency gradient of the G84E mutation across the European continent, with the mutation being more common in Nordic countries, notably Finland. This finding highlights the strength of the current study as family-based association methods provide the strongest protection against type I error due to population stratification. It remains to be seen how various analytic methods (e.g. those based on principal components that capture the major sources of genetic variation between subjects across common genetic variants) will protect against population stratification when analyzing uncommon genetic variants that disproportionately occur in specific European-derived populations in case-control settings.

In summary, analysis of the large ICPCG family collection establishes the $H O X B 13$ G84E allele as a reproducible risk factor for prostate cancer. Our identification of a common haplotype among the majority of HOXB13 G84E carriers indicates that there is a founder effect with a higher frequency of the mutant allele in Nordic populations. Additional studies using populationbased case-control and/or familial samples will be useful to define the penetrance of this mutation, which will have important clinical implications for families that carry the G84E mutation.

Acknowledgments We would like to express our gratitude to the many families who participated in the studies involved in the International Consortium for Prostate Cancer Genetics (ICPCG). The ICPCG is funded by a grant from the National Institutes of Health U01 CA89600 (to W.B.I.). Additional support to members within the ICPCG is as follows: University of Michigan Group acknowledges NIH grants R01 CA79596, R01 CA079596-10-S1 (ARRA), R01 CA136621, and P50 CA69568. University of Utah Group: The authors thank the support from the University of Utah Huntsman Cancer Institute (to Lisa A. Cannon-Albright). FHCRC/NHGRI Group: Partial support was provided by the Fred Hutchinson Cancer Research Center (to Janet L. Stanford) and National Human Genome Research Institute (to Elaine A. Ostrander). ACTANE Group: We acknowledge support from CR-UK grant C5047/A7357 and the NIHR to the Biomedical Research Centre at The Institute of Cancer Research and Royal Marsden NHS Foundation Trust and Prostate Action (to Ros Eeles), and Cancer Research UK (to Doug Easton). This work was also supported by the European Commission's Seventh Framework Programme grant agreement $n^{\circ} 223175$ (HEALTHF2-2009-223175), University of Umeå Group: Partial support was provided by Swedish Cancer Society and a Spear grant from the Umeå University Hospital, Umeå, Sweden (to Henrik Grönberg). University of Tampere Group: Partial support was provided from The Competitive Research Funding of the Pirkanmaa Hospital District (9M094), Finnish Cancer Organisations, Sigrid Juselius Foundation and Academy of Finland (116437 and 251074) (to Johanna Schleutker). Australian Group: Recruitment was funded by Cancer Council Victoria, Tattersalls and The Whitten Foundation; JLH is an Australia Fellow of the National Health and Medical Research Council. Northwestern University Group: Partial support was provided from Robert $\mathrm{H}$ Lurie Comprehensive Cancer Center and the Urological Research Foundation (to William J. Catalona). LSUHSC-NO Group: Louisiana Board of Regents, Centers for Disease Control and Prevention. Data Coordinating Center: Partial support was provided by NCI CA119069 and CA129684 (to Jianfeng Xu). We also thank other investigators who contributed to this work: ACTANE Group: Daniel Leongamornlert, Ed Saunders, Malgorzata Tymrakiewicz, Lynne O'Brien, Emma Sawyer, Rosemary Wilkinson, and Stephen Edwards from The Institute of Cancer Research, Sutton, Surrey; Jacques Simard, from the Human Molecular Endocrinology Research Center, CHUL Research Center, Laval University, Quebec City, Canada; Timothy Bishop from Cancer Research UK, Genetic Epidemiology Laboratory, St James' University Hospital, Leeds, UK; Michael Badzioch; Tokhir Dadaev, Lesley McGuffog, Koveela Govindasami, and Michelle Guy from the UKGPCS Team. University of Ulm Group: Antje Rinckleb and Mark Schrader from Department of Urology, University of Ulm, Germany; Josef Hoegel and Christian Kubisch from Institute of Human Genetics, University of Ulm, Germany; and Kathleen Herkommer from Department of Urology, Technical University of Munich, Germany. Fred Hutchinson Cancer Research Center Group: Laura McIntosh. We thank Liesel FitzGerald for helpful comments and review. William Foulkes thanks Celia Greenwood for advice. 
Open Access This article is distributed under the terms of the Creative Commons Attribution License which permits any use, distribution, and reproduction in any medium, provided the original author(s) and the source are credited.

\section{References}

Agalliu I, Karlins E, Kwon EM et al (2007) Rare germline mutations in the BRCA2 gene are associated with early-onset prostate cancer. Br J Cancer 97:826-831

Akamatsu S, Takata R, Haiman CA et al (2012) Common variants at $11 \mathrm{q} 12,10 \mathrm{q} 26$ and $3 \mathrm{p} 11.2$ are associated with prostate cancer susceptibility in Japanese. Nat Genet 44(426-9):S1

Bodmer W, Bonilla C (2008) Common and rare variants in multifactorial susceptibility to common diseases. Nat Genet 40(6):695-701

Carpten J, Nupponen N, Isaacs S et al (2002) Germline mutations in the ribonuclease $\mathrm{L}$ gene in families showing linkage with HPC1. Nat Genet 30:181-184

Cropp CD, Simpson CL, Wahlfors T, Ha N, George A, Jones MS, Harper U, Ponciano-Jackson D, Green TA, Tammela TL, BaileyWilson J, Schleutker J (2011) Genome-wide linkage scan for prostate cancer susceptibility in Finland: evidence for a novel locus on $2 \mathrm{q} 37.3$ and confirmation of signal on 17q21-q22. Int $\mathrm{J}$ Cancer 129:2400-2407

Edwards SM, Kote-Jarai Z, Meitz J et al (2003) Two percent of men with early-onset prostate cancer harbor germline mutations in the BRCA2 gene. Am J Hum Genet 72:1-12

Eeles RA, Kote-Jarai Z, Giles GG et al (2008) Multiple newly identified loci associated with prostate cancer susceptibility. Nat Genet 40:316-321

Eeles RA, Kote-Jarai Z, Al Olama AA et al (2009) Identification of seven new prostate cancer susceptibility loci through a genomewide association study. Nat Genet 41:1116-1121

Ewing CM, Ray AM, Lange EM et al (2012) Germline mutations in HOXB13 and prostate-cancer risk. N Engl J Med 366:141-149

Gillanders EM, Xu J, Chang BL et al (2004) Combined genome-wide scan for prostate cancer susceptibility genes. J Natl Cancer Inst 96:1240-1247

Gudmundsson J, Sulem P, Manolescu A et al (2007a) Genome-wide association study identifies a second prostate cancer susceptibility variant at $8 \mathrm{q} 24$. Nat Genet 39:631-637

Gudmundsson J, Sulem P, Steinthorsdottir V et al (2007b) Two variants on chromosome 17 confer prostate cancer risk, and the one in TCF2 protects against type 2 diabetes. Nat Genet 39:977-983

Gudmundsson J, Sulem P, Rafnar T et al (2008) Common sequence variants on $2 \mathrm{p} 15$ and Xp11.22 confer susceptibility to prostate cancer. Nat Genet 40:281-283

Gudmundsson J, Sulem P, Gudbjartsson DF et al (2009) Genomewide association and replication studies identify four variants associated with prostate cancer susceptibility. Nat Genet 41:1122-1126

Haiman CA, Chen GK, Blot WJ et al (2011) Genome-wide association study of prostate cancer in men of African ancestry identifies a susceptibility locus at 17q21. Nat Genet 43:570-573

Iyengar SK, Elston RC (2007) The genetic basis of complex traits: rare variants or "common gene, common disease". Methods Mol Biol 376:71-84

Kote-Jarai Z, Olama AA, Giles GG et al (2011a) Seven prostate cancer susceptibility loci identified by a multi-stage genomewide association study. Nat Genet 43:785-791

Kote-Jarai Z, Leongamornlert D, Saunders E, Tymrakiewicz M, Castro E, Mahmud N, Guy M, Edwards S, O’Brien L, Sawyer E, Hall A, Wilkinson R, Dadaev T, Goh C, Easton D, UKGPCS
Collaborators, Goldgar D, Eeles R (2011b) BRCA2 is a moderate penetrance gene contributing to young-onset prostate cancer: implications for genetic testing in prostate cancer patients. Br J Cancer 105(8):1230-1234. doi:10.1038/bjc.2011.383

Kruglyak L, Daly MJ, Reeve-Daly MP, Lander ES (1996) Parametric and nonparametric linkage analysis: a unified multipoint approach. Am J Hum Genet 58:1347-1363

Lange EM, Gillanders EM, Davis CC et al (2003) Genome-wide scan for prostate cancer susceptibility genes using families from the University of Michigan prostate cancer genetics project finds evidence for linkage on chromosome 17 near BRCA1. Prostate 57:326-334

Lange EM, Robbins CM, Gillanders EM et al (2007) Fine-mapping the putative chromosome 17q21-22 prostate cancer susceptibility gene to a $10 \mathrm{cM}$ region based on linkage analysis. Hum Genet 121:49-55

Purcell S, Neale B, Todd-Brown K et al (2007) PLINK: a tool set for whole-genome association and population-based linkage analyses. Am J Hum Genet 81:559-575

Schaid DJ, Chang BL (2005) Description of the international consortium for prostate cancer genetics, and failure to replicate linkage of hereditary prostate cancer to 20q13. Prostate 63:276-290

Sun J, Zheng SL, Wiklund F et al (2008) Evidence for two independent prostate cancer risk-associated loci in the HNF1B gene at $17 \mathrm{q} 12$. Nat Genet 40:1153-1155

Takata R, Akamatsu S, Kubo M et al (2010) Genome-wide association study identifies five new susceptibility loci for prostate cancer in the Japanese population. Nat Genet 42:751-754

Tavtigian SV, Simard J, Teng DH et al (2001) A candidate prostate cancer susceptibility gene at chromosome $17 \mathrm{p}$. Nat Genet $27: 172-180$

Thomas G, Jacobs KB, Yeager M et al (2008) Multiple loci identified in a genome-wide association study of prostate cancer. Nat Genet 40:310-315

Xu J, Zheng SL, Komiya A et al (2002) Germline mutations and sequence variants of the macrophage scavenger receptor 1 gene are associated with prostate cancer risk. Nat Genet 32: 321-325

Xu J, Dimitrov L, Chang BL et al (2005) A combined genomewide linkage scan of 1,233 families for prostate cancer-susceptibility genes conducted by the international consortium for prostate cancer genetics. Am J Hum Genet 77:219-229

Xu J, Zheng SL, Isaacs SD et al (2010) Inherited genetic variant predisposes to aggressive but not indolent prostate cancer. Proc Natl Acad Sci USA 107:2136-2140

Yeager M, Orr N, Hayes RB et al (2007) Genome-wide association study of prostate cancer identifies a second risk locus at 8q24. Nat Genet 39:645-649

Yeager M, Chatterjee N, Ciampa J et al (2009) Identification of a new prostate cancer susceptibility locus on chromosome 8q24. Nat Genet 41:1055-1057

\section{NOTE Added in Proof:}

While this manuscript was under review, several papers (1-4) demonstrating the significant association of HOXB13 G84E with prostate cancer risk, in familial as well as population-studies, were published, further establishing this mutation as a prostate cancer susceptibility allele.

1. Akbari MR, Trachtenberg J, Lee J, Tam S, Bristow R, Loblaw A, Narod SA, Nam RK. Association between Germline HOXB13 G84E Mutation and Risk of Prostate Cancer. J Natl Cancer Inst. 2012 Jul 9. [Epub ahead of print]. PMID: 22781434 [PubMed—as supplied by publisher] 
2. Breyer JP, Avritt TG, McReynolds KM, Dupont WD, Smith JR. Confirmation of the HOXB13 G84E Germline Mutation in Familial Prostate Cancer. Cancer Epidemiol Biomarkers Prev. 2012 Aug;21(8):1348-53. Epub 2012 Jun 19. PMID: 22714738 [PubMedin process]

3. Karlsson R, Aly M, Clements M, Zheng L, Adolfsson J, Xu J, Grönberg H, Wiklund F. A Population-based Assessment of Germline
HOXB13 G84E Mutation and Prostate Cancer Risk. Eur Urol. 2012 Jul 20. [Epub ahead of print]. PMID: 22841674 [PubMed-as supplied by publisher]

4. Stott-Miller M, Karyadi DM, King T, Kwon EM, Kolb S, Stanford JL, Ostrander EA (2012) HOXB13 mutations in a population-based, case control study of prostate cancer. The Prostate (in press) 